\title{
LOW TEMPERATURE HEAT CAPACITY AND THERMODYNAMIC PROPERTIES OF ZINC FERRITE*
}

\author{
EDGAR F. WESTRUM, JR. and D. M. GRIMES \\ University of Michigan, Ann Arbor, Michigan, U.S.A. \\ (Received 4 February 1957)
}

\begin{abstract}
The heat capacity of zinc ferrite $\left(\mathrm{ZnFe}_{2} \mathrm{O}_{4}\right)$ has been determined over the range 5 to $350^{\circ} \mathrm{K}$. Molal values of $C_{p}, S^{0}$, and $H^{0}-H_{0}{ }^{0}$ computed from the thermal data are $32.99 \pm 0.03$ $\mathrm{cal} / \mathrm{deg}$., $36.01 \pm 0.03 \mathrm{cal} / \mathrm{deg}$., and $18.00 \pm 0.02 \mathrm{cal}$, respectively, at $298.15^{\circ} \mathrm{K}$. A co-operative thermal anomaly associated with antiferromagnetic ordering occurs at $9.5^{\circ}$ and extends toward higher temperatures probably as a consequence of persisting short range order.
\end{abstract}

\section{INTRODUCTION}

ZiNC ferrite, $\mathrm{ZnFe}_{2} \mathrm{O}_{4}$, crystallizes in the normal spinel structure. A well-tempered zinc ferrite is, therefore, characterized by having the iron atoms located at the centers of octahedra of oxygen atoms and the zinc atoms centered in tetrahedra of oxygen atoms. Conversely, an inverted spinel contains the divalent cation on octahedral sites; since there are twice as many octrahedral sites as tetrahedral sites in the spinel structure, half of the trivalent iron atoms also occupy octrahedral sites. Typically, the inverted spinels are ferrimagnetic and the normal spinels are paramagnetic at room temperature. Since the exchange interactions between cations on octahedral sites are antiferromagnetic in nature, some type of antiferromagnetic ordering may take place in zinc ferrite at low temperatures.

Although the fairly complex magnetic properties of ferrospinels have been extensively investigated by various techniques, few of these measurements have extended below $10^{\circ} \mathrm{K}$. Utilization of low temperature adiabatic calorimetry permits both the detection of magnetic transformations and the evaluation of the thermodynamic parameters associated with these phenomena. This calori-

* 'This work was done with the support of the U.S. Army Signal Corps through the Engineering Research Institute of the University of Michigan. A preliminary report of these studies appears in Conference on Magnetism and Magnetic Materials p. 64. American Institute of Electrical Engineers, New York (1955). metric technique is relatively sensitive, precise and, compared to more direct magnetic measurements (e.g., susceptibility), less subject to being masked by traces of ferromagnetic impurities.

The study of the low temperature thermal properties of a series of nickel-zinc ferrites ${ }^{(1)}$ of empirical formula $\mathrm{Ni}_{1-x} \mathrm{Zn}_{x} \mathrm{Fe}_{2} \mathrm{O}_{4}$ over the range $x=0.6$ to $x=0.9$ revealed an anomalously high heat capacity in the vicinity of $9^{\circ} \mathrm{K}$, the magnitude of which increases rapidly as $x$ approachcs unity. Recent measurements by FRIEDBERG et al. ${ }^{(2)}$ on a sample approximating zinc ferrite in composition confirmed the obvious extrapolation to $x=1$ in revealing the existence of an anomalous peak in the heat capacity of zinc ferrite $\left(\mathrm{ZnFe}_{2} \mathrm{O}_{4}\right)$ with a maximum near $9^{\circ} \mathrm{K}$ and a prominent "tail" on the high temperature side. Low temperature neutron diffraction studies by Hastings and CoRLiss(3) have demonstrated the existence of this transition and strongly suggest that it results from an antiferromagnetic ordering.

However, the thermal anomaly reported by FRIEDBERG $^{(4)}$ in zinc ferrite is considerably rounded and broadened compared to other co-operative transformations and reveals no evidence of a discontinuity in the derivative of the heat capacity with respect to temperature. Such deviation from the usual behavior of co-operative transitions might be expected as a consequence of partial inversion of the "normal" spinel structure, of inhomogeneity on an atomic scale, or of deviation from exact 
stoichiometry in the sample utilized in these measurements. Further investigation of the thermal properties of this substance was, therefore, considered relevant to the understanding of the ordering phenomenon.

\section{EXPERIMENTAL}

\section{Preparation of the ainc ferrite}

Preliminary investigation revealed the strong dependence on composition of the heat capacity of nickel-zinc ferrites in the vicinity of $10^{\circ} \mathrm{K}$. For reasons already indicated, (t) great care was exercised in the preparative technique to obtain, as nearly as possible, a stoichiometric, homogeneous, non-inverted sample of zinc ferrite.

Equimolal quantities of weighed, anhydrous, chemically pure $\mathrm{ZnO}$ and $\mathrm{Fe}_{2} \mathrm{O}_{3}$ were milled in a hardened-steel ball mill using a thin acetone slurry. After passing the slurry through a magnetic separator, the bulk of the acetone was decanted and the remainder evaporated. Cylindrical slugs of about $50 \mathrm{~g}$ mass were pressed; the surface layer was removed, and the slugs were fired in air at $1100^{\circ} \mathrm{C}$ for $14 \mathrm{hr}$. After furnace cooling, the slugs were sufficiently fragmented in a hardened-steel "diamond mortar" to pass a 30 mesh screen. These granules were reformed into slugs, fired at $1100^{\circ} \mathrm{C}$ for $12 \mathrm{hr}$, and gradually allowed to cool in the furnace to $30^{\circ} \mathrm{C}$ over a period of $16 \mathrm{hr}$. The resulting ferrite granules were of a uniform reddish-brown color throughout.

Gravimetric chemical determinations showed $46 \cdot 24 \pm$ $0 \cdot 1$ per cent iron (theoretical: $46 \cdot 33$ ) and $27 \cdot 2 \pm 0 \cdot 1$ per cent zinc (theoretical: $27 \cdot 12$ ). Spectro-chemical analyses revealed 0.01 to 0.1 per cent of $\mathrm{Al}$ and $\mathrm{Mn}$ and 0.001 to 0.01 per cent of $\mathrm{Ca}, \mathrm{Cu}, \mathrm{Mg}, \mathrm{Ni}$, and $\mathrm{Si}$. Stannous chloride redox titration indicates less than 0.1 per cent ferrous iron in the samples.

\section{Cryogenic technique}

The Mark I adiabatic cryostat used for these measurements has been described. ${ }^{(5)}$ Measurements were made in a calorimeter (Laboratory Designation W-9) which is similar in design and dimensions to $W-G^{(6)}$ except for the following modifications: only four conduction vanes were used, protection against possible corrosion was achieved by a $0.02 \mathrm{~mm}$ gold plate on the interior surfaces, and a weighed quantity of Apiezon $T$ vacuum grease was used to provide thermal conduction in the thermocouple sleeve and in the thermometer-heater well. The calorimeter contained $2.0 \mathrm{~cm}$ helium pressure to improve thermal conduction in the sample space. Temperatures were measured with a capsule-type platinum resistance thermometer (Labotatory Designation A-3) inserted within the heater sleeve in the wall. A $150 \Omega$ glass-fibreinsulated, constantan wire was bifilarly wound in a double-thread groove in the heater sleeve. The thermometer was calibrated by the National Bureau of Standards against the International Temperature Scale above $90^{\circ} \mathrm{K}$ and by comparison at 19 temperatures with the Bureau's platinum thermometers ${ }^{(7)}$ over the range $10-90^{\circ} \mathrm{K}$.
Below $10^{\circ} \mathrm{K}$ we established a provisional temperature scale by fitting the constants in the equation ${ }^{(8)} R=$ $A+B T^{2}+C T^{5}$ to the observed resistance of the thermometer at $10^{\circ} \mathrm{K}$, the resistance at the boiling point of helium, and $d R / d T$ at $10^{\circ} \mathrm{K}$. The temperature scale thus defined probably agrees with the thermodynamic scale to $0.1^{\circ}$ below $10^{\circ} \mathrm{K}, 0.03^{\circ}$ from 10 to $90^{\circ} \mathrm{K}$, and $0.05^{\circ}$ from 90 to $400^{\circ} \mathrm{K}$

Measurements of temperature and of electrical energy

Table 1. Molal heat capacity of zinc ferrite (in cal $/ \mathrm{deg}^{-1} \mathrm{~g} / \mathrm{mole}^{-1}$ )

\begin{tabular}{|c|c|c|c|}
\hline$T\left({ }^{\circ} \mathrm{K}\right)$ & $C_{p}$ & $T\left({ }^{\circ} \mathrm{K}\right)$ & $C_{p}$ \\
\hline \multicolumn{2}{|c|}{ Series I } & \multicolumn{2}{|c|}{ Series III (cont.) } \\
\hline $184 \cdot 44$ & $24 \cdot 00$ & $11 \cdot 82$ & 3.034 \\
\hline $193 \cdot 52$ & $25 \cdot 00$ & $12 \cdot 95$ & $2 \cdot 787$ \\
\hline $203 \cdot 27$ & $25 \cdot 99$ & $13 \cdot 66$ & $2 \cdot 635$ \\
\hline $212 \cdot 90$ & $26 \cdot 93$ & $14 \cdot 70$ & $2 \cdot 457$ \\
\hline $222 \cdot 68$ & $27 \cdot 80$ & $15 \cdot 85$ & $2 \cdot 271$ \\
\hline $232 \cdot 53$ & $28 \cdot 65$ & $16 \cdot 97$ & $2 \cdot 127$ \\
\hline $242 \cdot 39$ & $29 \cdot 43$ & $18 \cdot 31$ & 1.989 \\
\hline $252 \cdot 28$ & $30 \cdot 16$ & $20 \cdot 14$ & $1 \cdot 848$ \\
\hline $262 \cdot 21$ & $30 \cdot 85$ & $22 \cdot 28$ & 1.755 \\
\hline $272 \cdot 28$ & $31 \cdot 44$ & $24 \cdot 45$ & $1 \cdot 723$ \\
\hline $282 \cdot 53$ & $32 \cdot 10$ & $26 \cdot 74$ & $1 \cdot 749$ \\
\hline $292 \cdot 86$ & $32 \cdot 71$ & $29 \cdot 39$ & $1 \cdot 848$ \\
\hline $303 \cdot 14$ & $33 \cdot 25$ & $32 \cdot 55$ & $2 \cdot 045$ \\
\hline $313 \cdot 31$ & $33 \cdot 77$ & 36.01 & $2 \cdot 341$ \\
\hline $323 \cdot 41$ & $34 \cdot 23$ & $39 \cdot 61$ & $2 \cdot 716$ \\
\hline $333 \cdot 65$ & $34 \cdot 66$ & $43 \cdot 47$ & $3 \cdot 176$ \\
\hline $343 \cdot 93$ & $35 \cdot 11$ & $47 \cdot 72$ & $3 \cdot 740$ \\
\hline \multicolumn{2}{|c|}{ Series II } & & T \\
\hline $7 \cdot 81$ & $2 \cdot 6$ & \multicolumn{2}{|c|}{ Series IV } \\
\hline $8 \cdot 47$ & 3.9 & $17 \cdot 04$ & $2 \cdot 123$ \\
\hline $8 \cdot 87$ & 5.9 & $18 \cdot 69$ & 1.957 \\
\hline $9 \cdot 18$ & $7 \cdot 9$ & $52 \cdot 37$ & $4 \cdot 298$ \\
\hline $9 \cdot 41$ & $9 \cdot 2$ & $58 \cdot 05$ & $5 \cdot 246$ \\
\hline $9 \cdot 76$ & $6 \cdot 5$ & $64 \cdot 00$ & $6 \cdot 173$ \\
\hline $10 \cdot 18$ & $4 \cdot 17$ & 69.98 & $7 \cdot 115$ \\
\hline $10 \cdot 91$ & $3 \cdot 37$ & $76 \cdot 16$ & 8.097 \\
\hline \multicolumn{2}{|c|}{ Series III } & $89 \cdot 79$ & $10 \cdot 335$ \\
\hline $5 \cdot 50$ & 0.58 & $105 \cdot 53$ & 12.900 \\
\hline $6 \cdot 24$ & $1 \cdot 11$ & $111 \cdot 99$ & $13 \cdot 917$ \\
\hline $6 \cdot 82$ & $1 \cdot 50$ & $120 \cdot 25$ & $15 \cdot 232$ \\
\hline $7 \cdot 48$ & 2.08 & $128 \cdot 58$ & $16 \cdot 526$ \\
\hline $8 \cdot 46$ & $3 \cdot 28$ & $137 \cdot 08$ & $17 \cdot 81$ \\
\hline $8 \cdot 89$ & $5 \cdot 3$ & $146 \cdot 07$ & $19 \cdot 11$ \\
\hline $9 \cdot 39$ & $(8 \cdot 7)$ & $155 \cdot 56$ & $20 \cdot 42$ \\
\hline $9 \cdot 75$ & $(8 \cdot 3)$ & $165 \cdot 25$ & $21 \cdot 70$ \\
\hline $10 \cdot 38$ & 3.86 & 175.00 & $22 \cdot 90$ \\
\hline $11 \cdot 10$ & $3 \cdot 272$ & $184 \cdot 94$ & $24 \cdot 06$ \\
\hline
\end{tabular}


were made with an autocalibrated White double potentiometer. A timer operated by an electrically driven 240 -cycle tuning fork and amplifier automatically indicated the duration of the energy input. Three independent determinations of the heat capacity of the empty calorimeter have been made over the entire temperature range.

\section{RESULTS}

The experimental values of the observed molal heat capacity of zinc ferrite are presented in Table 1. These data include small corrections for the slight differences in the amounts of helium and solder between the full and the empty calorimeter and for the finite temperature increments used in the measurements. Since the data are listed in chronological sequence, the temperature increments of the individual determinations can be estimated from the adjacent mean temperatures.

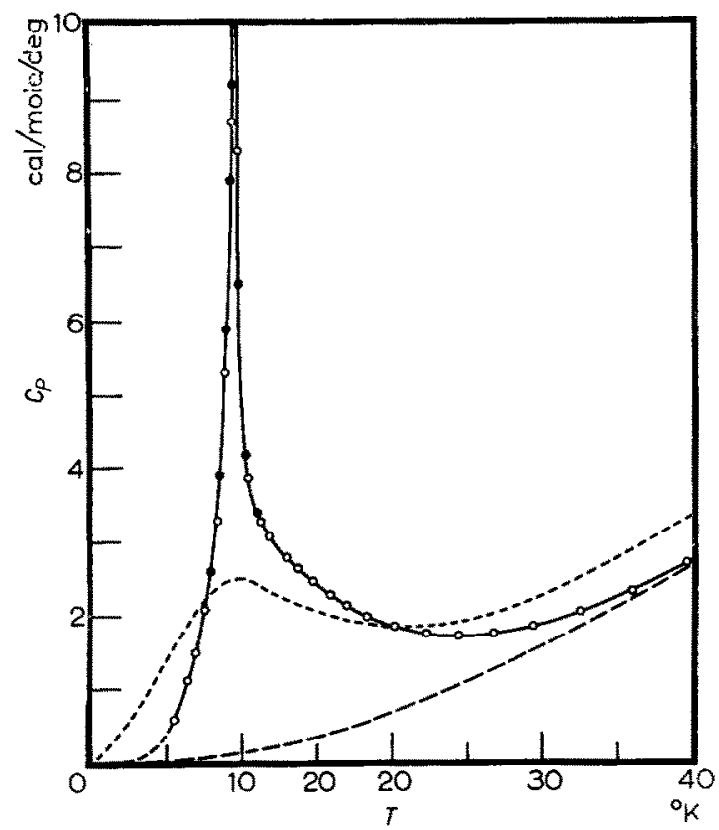

FIG, 1. The molal heat capacity of zinc ferrite from 5 to $40^{\circ} \mathrm{K}$. The dotted curve represents the measurements of Frienrerg et $a l^{(2)}$ and the dashed curve approximates the lattice (vibrational) heat capacity.

The data are expressed in terms of the defined thermochemical calorie equal to $4 \cdot 1840$ absolute joules. The ice point is taken as $273 \cdot 15^{\circ} \mathrm{K}$, and the gram formula weight of $\mathrm{ZnFe}_{2} \mathrm{O}_{4}$ as 241.08 . A sample of $163.397 \mathrm{~g}$ was employed. Fig. 1 depicts the heat capacity in the vicinity of the observed thermal anomaly.

The molal heat capacity and thermodynamic functions derived by numerical integrations of the heat capacity are listed at rounded temperatures in Table 2 . The heat capacity values were read from a smooth curve through the experimental points and are estimated to have a probable error of 0.1 per cent down to $25^{\circ} \mathrm{K}$ increasing to 1 per cent at $10^{\circ} \mathrm{K}$. The probable error may be 10 per cent below $10^{\circ} \mathrm{K}$ as a consequence of the sharp dependence of heat capacity on temperature over the region of thermal anomaly and the relatively slow establishment of thermal equilibrium in this region. 'The deviation of the individual experimental determinations from

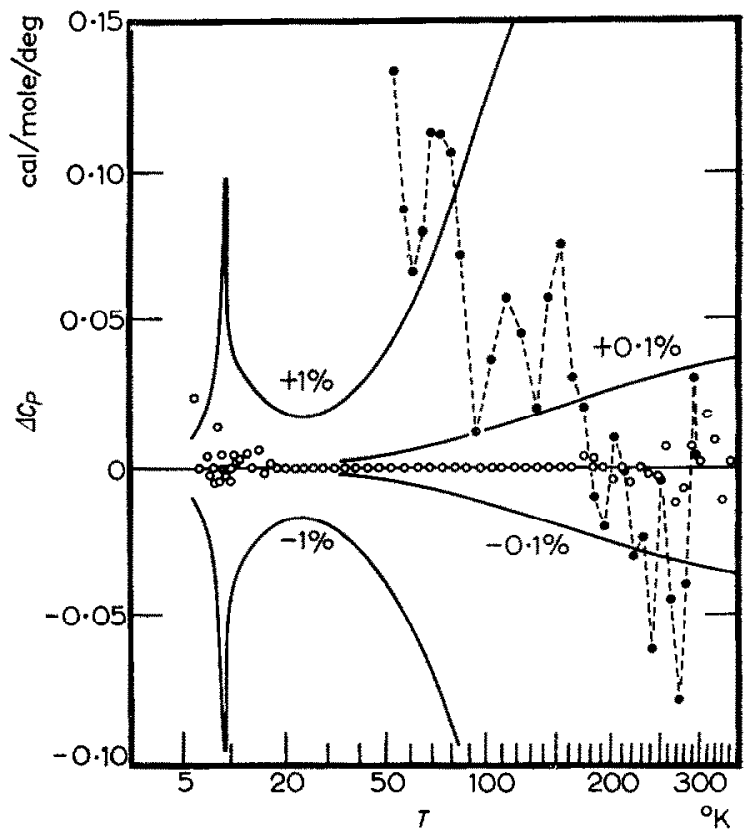

Fig. 2. The deviation of the measured heat capacities of zinc ferrite from smooth curve, i.e,

$$
\Delta C_{p}=C_{p \text { (exprimental deternination) }}-C_{p \text { (curve) }}
$$

The open circles represent the individual experimental determinations of this work. The solid circles are those reported by Kive. (a)

our smoothed curve are presented in Fig. 2. Solid lines represent deviations of $\pm 0 \cdot 1$ per cent and \pm 1.0 per cent, respectively. Below $5^{\circ} \mathrm{K}$, a Debye third power extrapolation was used to obtain values of the thermodynamic functions. The probable 
Table 2. Molal thermodynamic functions of zinc ferrite

\begin{tabular}{|c|c|c|c|c|}
\hline$T\left({ }^{0} \mathrm{~K}\right)$ & $\begin{array}{c}C_{p} \\
\text { (cal/deg.) }\end{array}$ & $\begin{array}{c}S^{0} \\
\text { (cal/deg.) }\end{array}$ & $\begin{array}{c}\left(H^{0}-H_{0}{ }^{0}\right) \\
(\mathrm{cal})\end{array}$ & $\begin{array}{c}-\frac{\left(F^{0}-H_{0}{ }^{0}\right)}{T} \\
\text { (cal } / \text { deg. })\end{array}$ \\
\hline 10 & $4 \cdot 68$ & $2 \cdot 2126$ & $17 \cdot 69$ & 0.4431 \\
\hline 15 & $2 \cdot 400$ & 3.4473 & $32 \cdot 65$ & 1.2705 \\
\hline 20 & 1.857 & $4 \cdot 0520$ & $43 \cdot 11$ & 1.8966 \\
\hline 25 & 1.724 & 4.4459 & 51.92 & 2.3692 \\
\hline 30 & 1.878 & 4.7701 & $60 \cdot 82$ & $2 \cdot 7427$ \\
\hline 35 & $2 \cdot 248$ & 5.0852 & 71.07 & 3.0548 \\
\hline 40 & $2 \cdot 758$ & 5.4173 & $83 \cdot 53$ & 3.3291 \\
\hline 45 & $3 \cdot 376$ & 5.7766 & $98 \cdot 82$ & 3.5807 \\
\hline 50 & 4.059 & $6 \cdot 1673$ & $117 \cdot 38$ & 3.8197 \\
\hline 60 & $5 \cdot 552$ & 7.0370 & 165.29 & 4.2821 \\
\hline 70 & $7 \cdot 117$ & 8.0095 & $228 \cdot 58$ & 4.7441 \\
\hline 80 & $8 \cdot 721$ & 9.0639 & 307.7 & $5 \cdot 2173$ \\
\hline 90 & $10 \cdot 368$ & $10 \cdot 1863$ & $403 \cdot 2$ & $5 \cdot 7067$ \\
\hline 100 & 12.004 & $11 \cdot 363$ & $515 \cdot 0$ & $6 \cdot 213$ \\
\hline 110 & 13.598 & $12 \cdot 583$ & $643 \cdot 1$ & 6.737 \\
\hline 120 & $15 \cdot 196$ & $13 \cdot 835$ & $787 \cdot 1$ & $7 \cdot 276$ \\
\hline 130 & 16.738 & $15 \cdot 112$ & 946.8 & 7.829 \\
\hline 140 & $18 \cdot 236$ & $16 \cdot 408$ & $1121 \cdot 7$ & $8 \cdot 396$ \\
\hline 150 & $19 \cdot 658$ & 17.715 & $1311 \cdot 2$ & 8.973 \\
\hline 160 & 2101 & 19.027 & $1514 \cdot 5$ & $9 \cdot 561$ \\
\hline 170 & $22 \cdot 29$ & $20 \cdot 339$ & $1731 \cdot 1$ & $10 \cdot 156$ \\
\hline 180 & $23 \cdot 48$ & $21 \cdot 648$ & 1960.0 & 10.759 \\
\hline 190 & $24 \cdot 62$ & 22.949 & $2200 \cdot 6$ & $11 \cdot 367$ \\
\hline 200 & $25 \cdot 67$ & $24 \cdot 239$ & $2452 \cdot 1$ & 11.979 \\
\hline 210 & $26 \cdot 65$ & $25 \cdot 515$ & $2713 \cdot 7$ & 12.592 \\
\hline 220 & $27 \cdot 56$ & $26 \cdot 776$ & $2984 \cdot 8$ & $13 \cdot 208$ \\
\hline 230 & $28 \cdot 43$ & $28 \cdot 020$ & $3264 \cdot 8$ & 13.825 \\
\hline 240 & $29 \cdot 25$ & $29 \cdot 247$ & $3553 \cdot 3$ & $14 \cdot 442$ \\
\hline 250 & $30 \cdot 00$ & $30 \cdot 458$ & $3849 \cdot 6$ & 15.059 \\
\hline 260 & $30 \cdot 70$ & $31 \cdot 647$ & $4153 \cdot 1$ & 15.673 \\
\hline 270 & $31 \cdot 34$ & $32 \cdot 818$ & $4463 \cdot 4$ & $16 \cdot 287$ \\
\hline 280 & 31.96 & 33.970 & 4779.9 & 16.899 \\
\hline 290 & $32 \cdot 54$ & $35 \cdot 102$ & $5102 \cdot 4$ & $17 \cdot 507$ \\
\hline 300 & 33.08 & $36 \cdot 214$ & $5430 \cdot 5$ & $18 \cdot 112$ \\
\hline 350 & $35 \cdot 35$ & 41.493 & $7143 \cdot 8$ & 21.082 \\
\hline $273 \cdot 15$ & $31 \cdot 54$ & $33 \cdot 184$ & 4562.7 & $16 \cdot 481$ \\
\hline $298 \cdot 15$ & 32.99 & $36 \cdot 010$ & $5369 \cdot 8$ & 18.000 \\
\hline
\end{tabular}


errors in the entropy, enthalpy, and free energy function are estimated to be $0 \cdot 1$ per cent above $100^{\circ} \mathrm{K}$, but for internal consistency one more digit has been retained than is justified by the estimated probable error. The effect of nuclear spin and isotope mixing is not included in the entropy and the free energy function.

\section{DISCUSSION}

After the completion of these measurements, heat capacity data on zinc ferrite from 51 to $298^{\circ} \mathrm{K}$ were reported by $\mathrm{K}_{\mathrm{ING}}$ ( $^{(9)}$ The deviations of KING's data from our smoothed curve are shown in Fig. 2. The data of King trend gradually to higher values toward lower temperatures than do the results of the present research; however, the agreement is good at room temperature. By virtue of compensation of these deviations of opposite sign, the entropy increments $\left(S_{298 \cdot 16^{\circ} \mathrm{K}}-S_{51^{\circ} \mathrm{K}}\right)$ are in close agreement. Below $51^{\circ} \mathrm{K}$, the extrapolated portion of KING's entropy is in error by nearly four units. This emphasizes the desirability of extending heat capacity measurements to the lowest practicable temperatures when such data are intended for evaluation of chemical thermodynamic functions, Isolated experimental points obtained by FrIEDBERG et $a l .{ }^{(2)}$ over the range 80 to $200^{\circ} \mathrm{K}$ appear to be at least 5 per cent higher than those reported either in the present work or by KING.

The existence of a typical co-operative typc hcat capacity anomaly rising to a sharp maximum greater than $9 \mathrm{cal} / \mathrm{mole} / \mathrm{deg}$. at $9 \cdot 5 \pm 0 \cdot 2^{\circ} \mathrm{K}$ accompanied by a prominent "tail" possibly extending beyond $25^{\circ} \mathrm{K}$ is characteristic of pure zinc ferrite. However, because thermal equilibrium was so slowly achieved below $10^{\circ} \mathrm{K}$, it was desirable to traverse this entire anomaly with a single energy input and then to compare the directly measured enthalpy with that obtained by the integration of the $C_{p}$ curve (Fig. 1) over the corresponding range. The results of three such tests are summarized in Table 3 and indicate good accord with the heat capacity measured with small temperature increments.

The anomaly as reported by FRIEDBERG et al.,(2) is indicated by the dotted line in Fig. 1. The observed difference is probably due to deviations from exact stoichiometry, from inhomogeneity, and/or from partial inversion suggested by the mode of preparation and the reported properties of their sample. ${ }^{(2,4)}$ That the thermal history of the ferrite specimen may have a marked effect on heat capacity over a wide temperature range has recently been demonstrated for lithium-zinc ferrite. ${ }^{(10)}$

\section{Table 3. Comparison of measured and integrated} enthalpy increments

\begin{tabular}{c|c|c|c}
\hline$\left.T_{\text {initial }}{ }^{\circ} \mathrm{K}\right)$ & $\left.T_{\text {finat }}{ }^{\circ} \mathrm{K}\right)$ & $\Delta H_{\text {measured }}$ & $\Delta H_{\text {integrated }}$ \\
\hline 5.16 & $25 \cdot 23$ & 52.7 & 51.7 \\
5.03 & 14.12 & 31.6 & 30.0 \\
5.03 & 16.07 & 36.7 & 36.1 \\
\hline
\end{tabular}

Although it is not yet possible satisfactorily to resolve the magnetic and lattice contributions to the specific heat, a rough approximation may be obtained by fitting the higher temperature data with an empirical equation of the type recommended by KeLLeY.(11)

The Debye and Einstein function sum proposed by $\mathrm{KING}^{\left({ }^{9}\right)}$ was modified to better fit our data. The equation

$$
C_{p}=D(178 / T)+3 E(390 / T)+3 E(710 / T)
$$

fits our data to within 0.5 per cent over the range 130 to $300^{\circ} \mathrm{K}$. This approximate lattice heat capacity is presented as a dashed curve in Fig. 1. Attempts to make a similar extrapolation from temperatures substantially lower than $130^{\circ} \mathrm{K}$ resulted in a calculated lattice heat capacity contribution in excess of the measured total value near $40^{\circ} \mathrm{K}$. Hence the estimated value of the lattice contribution is almost certainly high over the entire range.

If the magnetic contribution is estimated as the difference of this and the experimental curve, the magnetic entropy is $2.2 \mathrm{cal} / \mathrm{mole} / \mathrm{deg}$. at $10^{\circ} \mathrm{K}, 4 \cdot 0$ at $25^{\circ} \mathrm{K}$, and 4.5 at $150^{\circ} \mathrm{K}$. The molal entropy increment between the completely disordered paramagnetic states and the ordered antiferromagnetic state is $2 R \ln (2 S+1)=7 \cdot 12(\mathrm{cal} / \mathrm{mole} / \mathrm{deg})$. The discrepancy between the theoretical value and our rough estimate of the magnetic contribution can readily be explained if we assume the persistence of short range ordering contributions to the thermal properties above $130^{\circ} \mathrm{K}$.

These data are thus seen to be in accord with the interpretation of HASTINGS and CoRLISs ${ }^{(3)}$ of 
the transition from paramagnetic zinc ferrite to an antiferromagnetic state at $9.5^{\circ} \mathrm{K}$ as a result of the spin interaction of the iron atoms. The anomalously high heat capacity above $9.5^{\circ} \mathrm{K}$ is consistent with the persistence of short range ordering above the Néel temperature and the interpretation of the diffuse scattering of neutrons observed at liquid nitrogen temperatures as arising from a shortrange ferromagnetic interaction.

Note added in proof: The heat capacity here reported is consistent with the results calculated by Tachik and Yosida, Progr. Theor. Phys., Osaka 17, 223 (1957).

Acknowledgements-The authors appreciate the generous co-operation of Prof. H. W. WeLch, JR. of the Electrical Engineering Department, the assistance of JAMES KUIPER in the preparation of the sample, of Dr. CHIEN Chov and SeIsho TOMEODA in the cryogenic measurements and of Te Fu Chang in the calculations.

\section{REFERENCES}

1. Grimes D. M. and Westrum E. F., Jr. Submitted to F. Phys. Chem.

2. Frimdererg S. A. et al. Investigations of Thermal and Electrical Properties of Solids at Very Low Temperature Carnegie Institute of Technology Report (1955).

3. Corliss L. M. and Hastings J. M. Acta Cryst. 7, 674 (1954); Phys. Rev. 102, 1460 (1956).

4. Friedeerg S. A. and Burk D. L. Low Temperature Heat Capacity of Some Normal Spinels Conference on Magnetism and Magnetic Materials American Institute of Electrical Engineers, New York (1955).

5. Westrum E. F, Jr. and Beale A. F., Jr. F. Amer. Chem. Soc. Submitted.

6. Benjamins E. and Westrum E. F., Jr. 7 . Amer. Chem. Soc. 79, 287-290 (1957).

7. Hoce H. H. and Brickwedee F. G. F. Res. Nat. Bur. Stand. 22, 351 (1939).

8. Osborne N. S., Stimson H. F., Sligh T. S., JR., and Cragoe C. S. Bur. Stand. Sci. Papers 20,65 (1925).

9. King E. G. Y. Phys. Chem. 60, 410 (1956).

10. Westrum E. F. and Grimes D. M. To be published.

11. Kelley K. K. Contributions to the Data on Theoretical Metallurgy XI U.S. Bureau of Mines Bulletin 477. Washington D.C. (1950). 